\title{
RECYCLING AS A CRISIS OF MEANING
}

\author{
By Max Liboiron
}

In laymen's terms, recycling is "good for the environment." It involves “doing your bit" to help "save the Earth." Yet, recycling requires high expenditures of energy and virgin materials, and produces pollutants, greenhouse gases and waste; it creates products that are "down-cycled" because they are not as robust as their predecessors, nor are such products usually recyclable themselves. Of the fifteen to thirty percent of recyclables that are retrieved from the waste stream, "almost half" are buried or burned due to contamination or market fluctuations that devalue recyclables over virgin materials (McDonough and Braungart, 56-60; Rogers, 176-179; Luke, 115-135; Rathje, 203-7; MacBride; Ackerman; EPA; Grassroots Recycling Network, Taxpayers for Common Sense, Materials Efficiency Project and Friends of the Earth). Furthermore, recycling infrastructure creates a framework where disposables become naturalized commodities instead of allowing practices of waste redesign, reduction or elimination.

How is the schism between the popular perception of recycling as "good for the environment" and its less environmentally sound industrial processes maintained? By critiquing the visual culture of recycling campaigns, I argue that the meaning of recycling has been decontextualized, narrowed, and naturalized, thus functioning as a commoditysign. That is, recycling has been "abstracted from [its] context and then reframed in terms of the assumptions and interpretive rules of the advertising framework" through which it is promoted (Goldman, 5). I identify three main characteristics of the recycling commodity-sign. First, the individual, rather than government or industry, is represented as the primary unit of social change. Secondly, recycling is depicted as an act that ends at 
the blue bins, cutting out the industrial side of the cycle. Finally, recycling is symbolized as something that benefits the environment "in general" rather than as a specific form of waste management. Overall, I argue that recycling, instead of being a solution to environmental or waste crises, in fact constitutes a crisis of meaning that allows environmental degradation and derisory waste practices to continue.

\section{The Lone Activist}

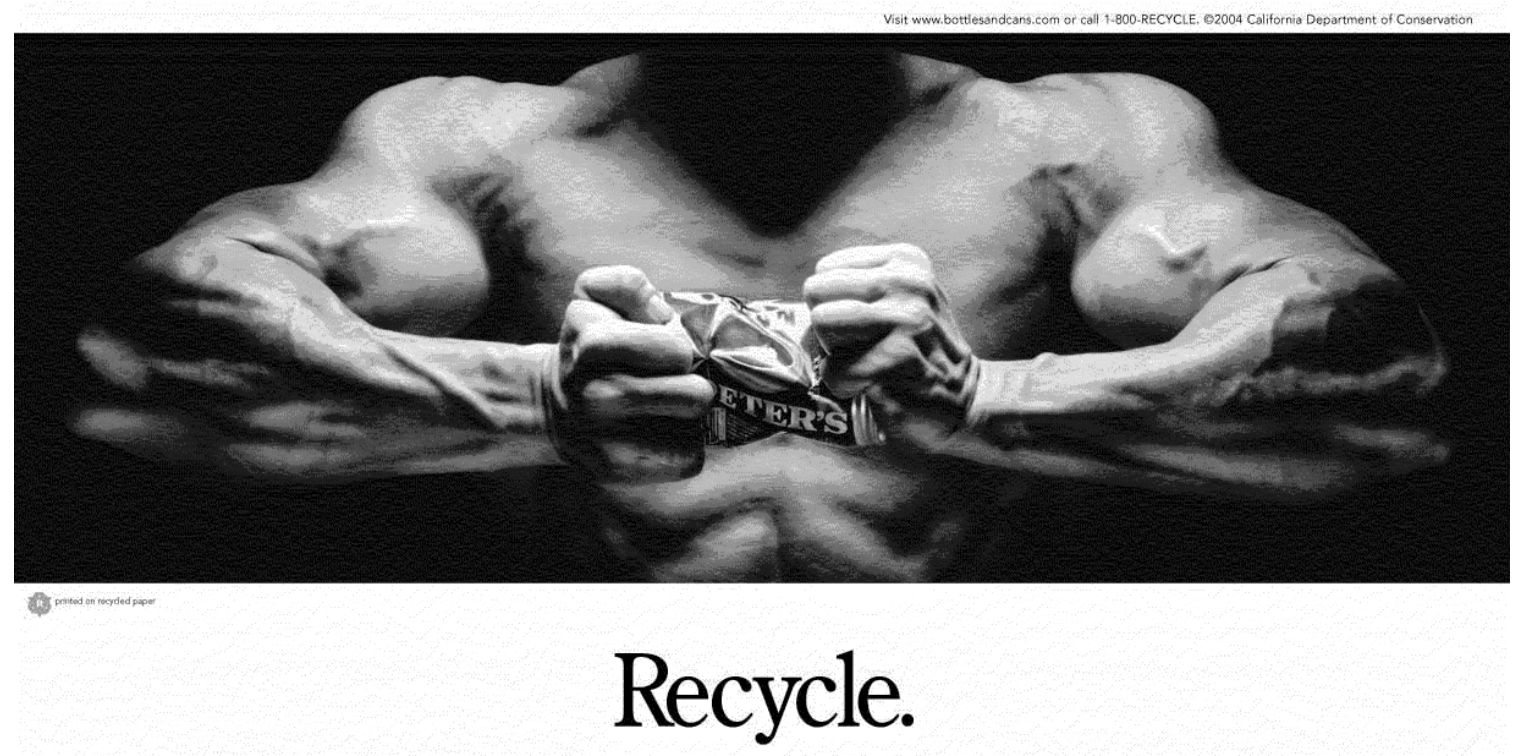

Recycle. California Department of Conservation, 2004.

An intensely muscled male torso crushes a can between his hands. Underneath this image, in bold black text, it simply reads: "Recycle." Part of the California Department of Conservation's 2004 recycling campaign, this humorous poster is aligned with various recycling superheroes, including Max Man (Rhode Island Resource Recovery Corporation), WOW! Man (Western Oregon Waste), and Captain Recycle and 
the Ozone Friends (Ican Design, UK). Each campaign implies that one person can—and routinely does-"make a difference." The superhero trope is one way that recycling promotes what some scholars call "individualization," or an individual response to a collective problem (Maniates; Szasz). By promoting elective individual actions, recycling (and green consumerism in general) becomes an asocial, apolitical form of environmental response that forecloses the apparent need for dealing with solid waste at a more systemic level (such as industry or government) with more systemic means (collectives, policies or institutions).

A second genre of ads, such as one that reads: "Recycle! Save the planet you love so others can love it too!” (Andrew Meguelez, 2008), graphically emphasize yet mystify the relationship between individual actions and the global environment. Recycling is thought to help "save the planet." Such discourse introduces a crisis of scale, and thus of agency. How can individuals possibly contend with the Herculean task of saving the planet, especially when the tools afforded to us are blue bins and pop bottles? The problem and the solution do not correspond.

In addition to the discourse about local actions and global crises, there is a second way in which this crisis of scale plays out via recycling. For every ton of municipal solid waste, seventy tons are produced by industry (Rogers, 4). Of municipal solid waste, only thirty percent is residential waste (Wagner, 3). Of that, forty percent is recyclable. In the US, the average recycling rate is thirty-three percent (EPA, 3). Thus, much less than half a percent of waste generated in the United States is "managed" through household 
recycling. ${ }^{1}$ This is not to say that household recycling is rubbish, but that it can only affect the waste proper to its tiny domain. Part of the issue is that municipal, and particularly residential, solid waste has been naturalized to mean solid waste in general, making industrial solid waste invisible; municipal waste is much more visible in our daily lives, in recycling campaigns, and in news stories. As such, campaigns can imagine the work that household recycling does on a global scale.

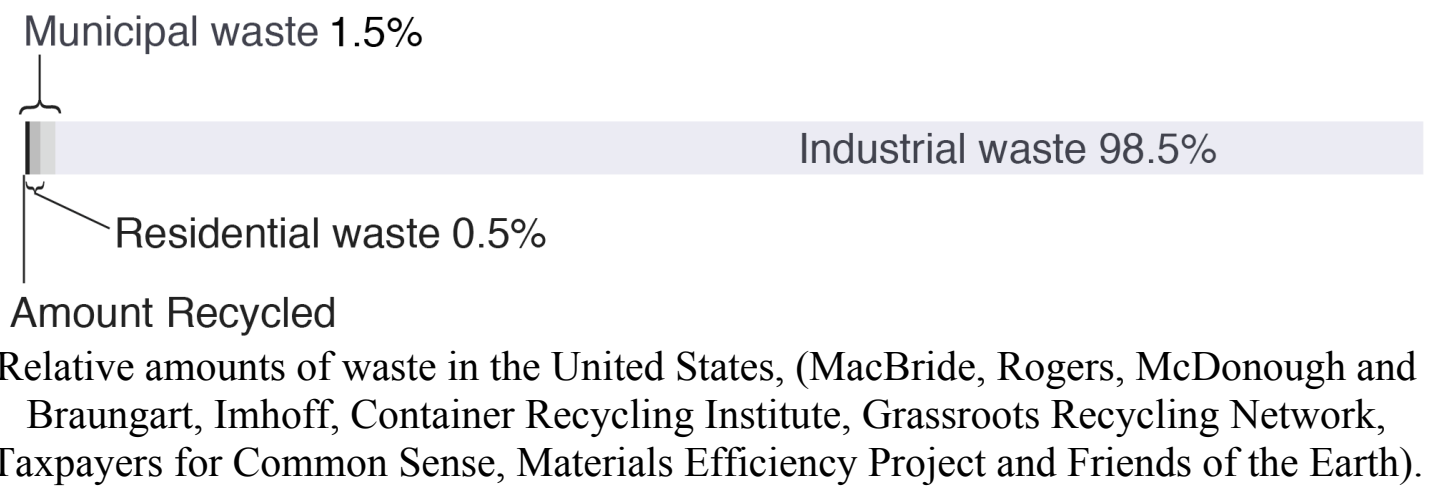

\section{The Magically Closed Loop}

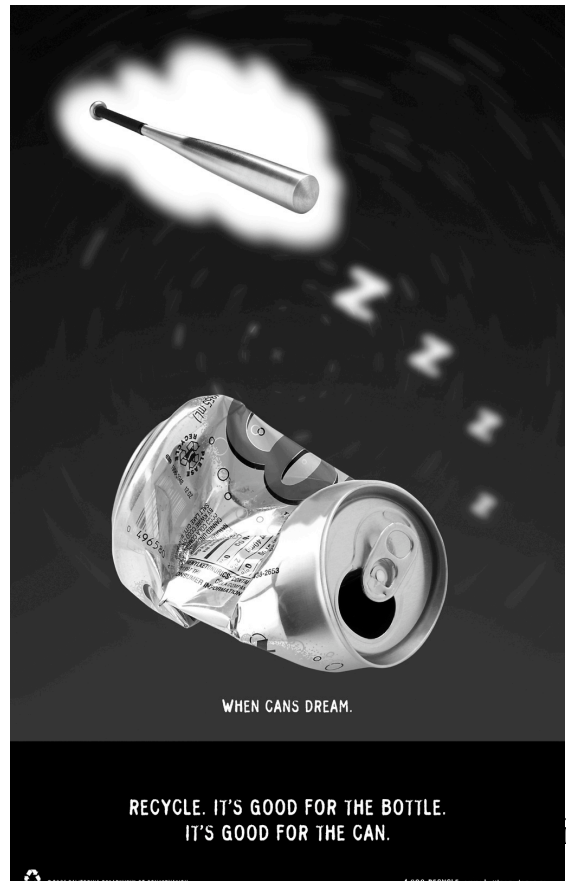

Another way that the visual culture of recycling maintains the gap between environmentally-motivated individual recycling and its less environmentally sustainable material processes is by abstracting and mystifying the industrial side of the "loop." A poster by Red Squirrel Design that depicts “The Recycling Process" is just one example: bottles, cans, and paper enter a round, floating machine with dials and steam,

Recycle. It's Good for the Bottle. It's Good for the Can. California Department of Conservation, 
and emerge at the bottom as bottles, cans, and paper. The process that transforms the objects from themselves into themselves seems magical. Another example is the "Recycle. It's Good for the Bottle. It's Good for the Can" campaign. In this series, aluminum cans dream of becoming baseball bats, and plastic water bottles dream of becoming fleece jackets. In both cases, the industrial process is acknowledged, yet represented as a magical, non-specific transformative process. "Recycling" is homogenized into one general procedure, insinuating that all recycling is created (environmentally) equal, even though the smelting process for aluminum is very different from the bleaching process for paper. Furthermore, while the poster indicates a quick technological alteration, there are many steps in each process, several of which occur in other countries, and all of which have their own environmental costs. Finally, the abstraction of the industrial process allows recyclables and recycled materials, household environmentalism and industrial processes, to be made equivalent, when if fact they have radically different materialities, motivations, and environmental impacts. The absence of particulars about what enters the industrial process (virgin materials, energy, unpaid household labour, outsourcing contracts to Third World countries) and what its "externalities" are (pollution, toxins, and downgraded commodities) is the condition of possibility for the "closed loop" recycling symbol itself.

\section{Environmental Activism, period.}

Recycling is rarely represented as an industrial process, or as a form of waste management. Instead, its primary meaning comes from its status as a form of environmental activism. Yet just as recycling is abstracted from issues and processes of 
industry, government, or patterns of consumption, the activism associated with recycling is also abstracted and made equivalent to environmental activism in general. The inclusion of plants, animals, and beautiful landscapes in campaigns implies relationships between recycling and forest preservation, animal rights, ecological conservation, pollution control, and other environmental impacts. This appropriation of a sort of Gaia hypothesis, whereby every type of environmental act is linked to every environment, which promotes the act of recycling as one that "saves the earth."

\section{The Commodity Sign}

While space has not permitted a detailed or nuanced investigation of different messages, representations, and strategies of recycling campaigns, a trend has nonetheless emerged from the cases covered here. Instead of representing recycling as a form of industrial waste management, recycling is depicted as a form of individualized environmental activism "in general." All parts of this narrative rely on the abstraction, mystification, and misplaced equivalence of the recycling process so that the practice of recycling can come to mean the same thing as the recycling symbol; in laymen's terms, recycling is "good for the environment" because it reuses waste in a closed-loop cycle. The three chasing arrows of the universal recycling symbol becomes a commodity-sign for recycling.

A commodity-sign is formed when an image of a commodity becomes a signifier of a certain experience or meanings, such as when red sports cars stand in for "sexiness" (or, alternatively, "mid-life crisis"). The thing being signified -"sexiness"- is abstracted from the complex relationships, statuses, and contexts it exists in and is attached to a 
product or practice that has also been detached from its complex material and social world. To quote Robert Goldman in Reading Ads Socially, "[t]he semiotic reductionism necessary for producing a currency of commodity-signs involves transforming complex meaningful relations into visual signifiers. It then turns the relationship between signifier and signified into one of equivalence, so that the visual signifier can be substituted for the signified of the product" (6). The commodity-sign shifts values from the social realm onto commodities, or in this case, onto the practice of recycling. Through recycling campaigns, "the original totality of the signified slips from view" and recycling becomes, first and foremost, a type of environmental activism rather than a form of waste management or an industrial process (Goldman, 18).

This situation is systemic, and so does not have to be intentional, as Clara Rodriguez's well-intentioned artwork demonstrates. The designers that produce campaign material are not given a handbook about the industrial process of recycling and asked to impede waste reduction or community formation. The legibility of a campaign depends on its ability to be recognized by the public, which in turn depends on the advertisement's use of meanings that are already in common circulation. Yet using this interpretive currency and the creation of commodity-signs leads to an impoverishment of public language and meanings. In the case of recycling, this has acute consequences. For example, a poster advocating for the reuse of scrap paper reads, "This piece of paper used to advertise a Frisbee game. Now it serves a different purpose. Recycle." In this case, "reuse" is called "recycling," it is, after all, an environmentally motivated act involving recyclable waste. Through this slippage, "recycling" comes to denote its "competitors" in solid waste management, such as reduction, redesign and reuse. The narrowing of 
descriptive language for different types of environmental participation results in the obfuscation of waste alternatives by positing recycling as other alternatives, even when there is a hierarchy of environmental effectiveness between regulation, reduction, redesign, reuse, and recycling. This is a sign of the success and ubiquity of recycling as a commodity-sign, and signals a political failure to differentiate between ideologically diverse environmental actions.

This impoverishment of meaning, language, critical discourse, and action describes the proper crisis of recycling. Unlike many other crises, however, the danger is in the situation's stability rather than instability. Very few, if any, mainstream alternatives to recycling exist that can match its support, funding, and infrastructure. Furthermore, there is little room afforded to critical discourses that seek to find or fund such alternatives, partly due to the reasons outlined above. The crisis of recycling is that recycling has become the favoured and institutionalized form of environmental activism. As the Lastituto Recide campaign so clearly states, "If you don't recycle, recycle." It's a no-brainer. It's the obvious way to go. Recycle.

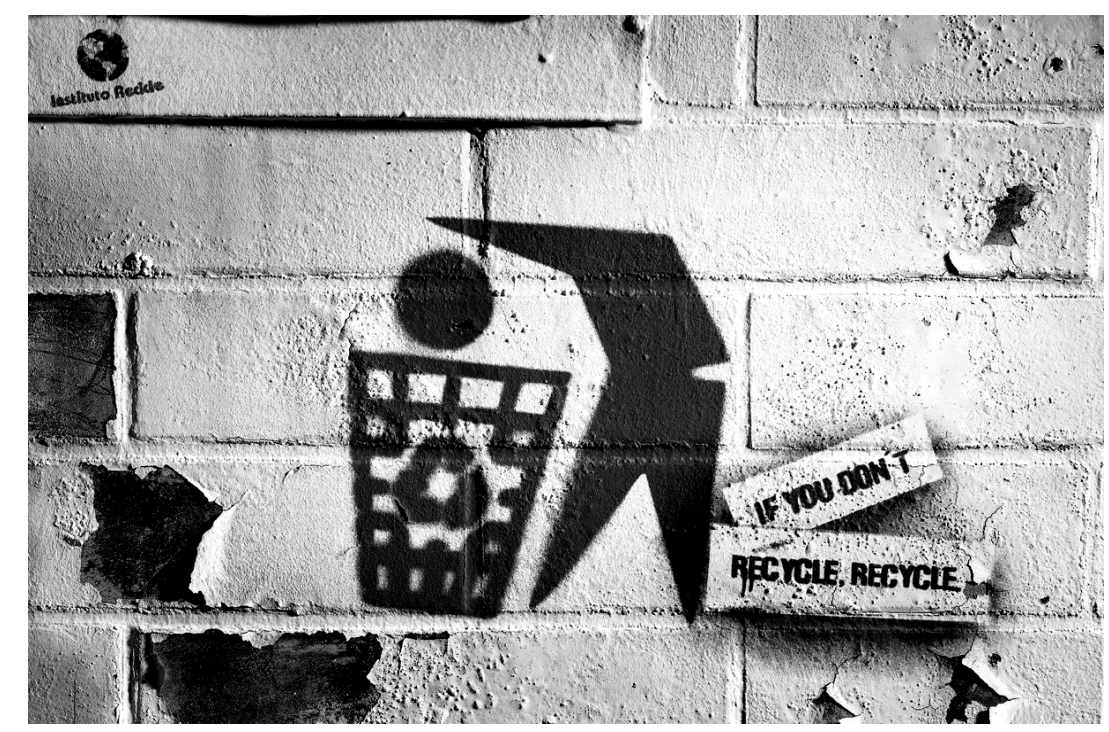

Lastituto Recide graffiti campaign, n.d. 


\section{Works Cited}

Ackerman, Frank. Why Do We Recycle?: Markets, Values, and Public Policy. Washington, D.C.: Island Press, 1997.

The Container Recycling Institute. "Graphs: Beverage Container Statistics.” Accessed 2007. http://www.container-recycling.org/all_rates.htm

EPA. Municipal Solid Waste Generation, Recycling, and Disposal in the United States: Facts and Figures for 2008. Washington, D.C.: United States Environmental Protection Agency, 2009.

Goldman, Robert. Reading Ads Socially. London and New York: Routledge, 1992.

GrassRoots Recycling Network, Taxpayers for Common Sense, Materials Efficiency Project and Friends of the Earth, Welfare for Waste: How Federal Taxpayer $\quad$ Subsidies Waste Resources and Discourage Recycling. Athens, GA: GrassRoots Recycling Network,1999.

Imhoff, Daniel. "Thinking outside of the Box.” Whole Earth. Winter, 2002.

Luke, Timothy W. Ecocritique: Contesting the Politics of Nature, Economy, and Culture. Minneapolis: University of Minnesota Press, 1997.

MacBride, Samantha. "Tonnage and Toxicity: Visible and Invisible Solid Waste Problems in the Contemporary United States.” Coles Science Salon Series. New York University, New York, 3 Nov. 2008.

Maniates, Michael. "Individualization: Plant a Tree, Buy a Bike, Save the World?" Confronting Consumption. Ed. Thomas Princen, Michael Maniates, Ken Conca. Cambridge, MA: MIT Press, 2002. 43-66.

McDonough, William, and Michael Braungart. Cradle to Cradle: Remaking the Way We Make Things. New York, NY: North Point Press, 2002.

Rathje, William, and Cullen Murphy. Rubbish! The Archeology of Garbage. Tucson, AZ: University of Arizona Press, 2001.

Rogers, Heather. Gone Tomorrow: The Secret Life of Trash. New York: The New Press, 2005.

Szasz, Andrew. Shopping Our Way to Safety: How We Changed from Protecting the Environment to Protecting Ourselves. Minneapolis, MN: University of Minnesota Press, 2007.

Wagner, Phillipa. Waste Management in the City of Calgary. Calgary, AB: City of Calgary, 2009. 